\section{DCCL: A Fundamental Dataset of Cervical Cancer Cytological Screen Using Deep Learning Technology}

\section{Shuanlong Che ${ }^{1}$, Dong Liu', Changzheng Zhang ${ }^{2}$, Dandan Tu and Pifu Luo ${ }^{1 *}$}

${ }^{1}$ Department of Pathology, KingMed Diagnostics Co., Ltd., Guangzhou, China

${ }^{2}$ Huawei, Shenzhen, China

A well-annotated dataset for the Artificial Intelligence (AI)-aided cervical cancer screen, so called Deep Cervical Cytology Lesions (DCCL) has been explored by a collaboration of King Med Diagnostics and Huawei in China. It is the largest set of cervical cytology data for development of the deep learning-based screening product, and it becomes a milestone and "A Benchmark for Cervical Cytology Analysis" as the authors indicated. This beautiful work has been presented at the $22^{\text {nd }}$ International Conference on Medical Image Computing and Computer Assisted Intervention (MICCAI, 2019, Shenzhen, China) [1], and published in the International Workshop on Machine Learning in Medical Imaging [2].

Cervical cancer is one of the most common malignant tumors threatening women's health, especially in the developing countries. It is preventable or curable if its precancerous lesions are early detected by cytological screening combined with Human Papilloma Virus (HPV) test. Due to severely lack of the screening personnel in China, the mortality and morbidity of cervical cancer remain high. An AI-Aided Screening Product (AI-ASP) for cervical cancer detection will be a solution because it helps to screen out the normal cervical specimens so that the cytologists can focus the diagnosis of abnormal lesions.

In the development of an AI-ASP for cervical screening, a large amount of high-quality and annotated cervical cytology dataset is an

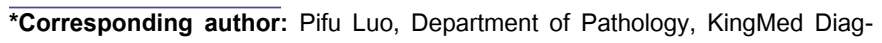
nostics Co., Ltd., Guangzhou, China, Tel: +86 02028078351; E-mail: gz-luopf@ kingmed.com.cn

Citation: Che S, Liu D, Zhang C, Tu D, Luo P (2019) DCCL: A Fundamental Dataset of Cervical Cancer Cytological Screen Using Deep Learning Technology. J Cytol Tissue Biol 6: 024.

Received: October 28, 2019; Accepted: November 19, 2019; Published: November 26, 2019

Copyright: () 2019 Che S, et al. This is an open-access article distributed under the terms of the Creative Commons Attribution License, which permits unrestricted use, distribution, and reproduction in any medium, provided the original author and source are credited. essential prerequisite for the deep learning algorithm. Lack of dataset for the deep learning training has become a bottleneck of developing any AI-aided product in medicine.

DCCL has collected a total of 14,432 image blocks from 1,167 complete slide images, which is the largest dataset for the deep learning training on cervical cancer screening. These images were selected from a huge volume of cervical pap smears stored in KingMed Diagnostics. KingMed is the largest commercial laboratory in China, and is also the first laboratory in China obtaining Laboratory Accreditation from the College of American Pathologists (CAP) and International Organization for Standardization 15189 (ISO15189). It has accumulated a total volume of 43.5 millions cervical cytological cases over last twenty years. In cervical cytological screening practice, KingMed completely follows the CAP and ISO15189 guidelines in its quality assurance and quality control program. These ensure a high standard resource of DCCL dataset both in quantity and quality.

Figure 1 illustrates the algorithm of DCCL dataset construction. Annotation was performed by eight senior cytopathologists, who have at least six years or above experience of signing-out in cytopathology. Two cytopathologists paired as a group, one does labeling and another does verification. Before the annotation process, cytopathologists were trained by Huawei AI engineers for the labeling standards and lessons to ensure the quality and accuracy of annotation, and to minimize the subjective difference among the cytopathologists. Two types of annotation were provided; one is the slide-level annotation for the normal result and second is cell-level annotation for the abnormal result. A total of 27,972 lesion cells were labeled following the diagnostic criteria and categories of the 2014 Bethesda System (TBS) for the Cervical Cytology Reporting [3]. The annotation results were also randomly checked by a chief cyto pathologist as the quality assurance process. Therefore, the annotation results of DCCL dataset are high quality and reliable.

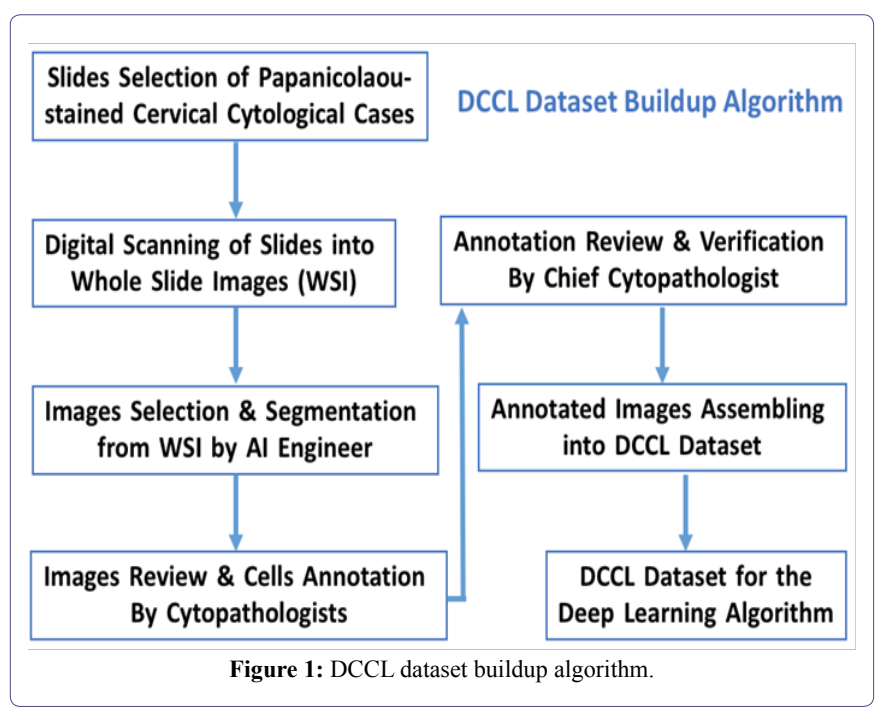


By using this DCCL dataset, a deep learning algorithm model has developed, which has achieved a sensitivity of $61 \%$ of the negative cytological cases signed-out by cytopathologists. In these cases, the accuracy rate is greater than $99 \%$ (i.e. less than $1 \%$ of false-negative rate). The algorithm has also achieved a $100 \%$ of sensitivity of the abnormal cases signed-out by cytopathologists, and no cases were missed among the abnormal ones by the deep learning screening algorithm.

In comparison with the currently available cervical cytological data sets including Cervi SCAN [4], ISBI 2015 [5] and recently published Datasets [6-8] included several hundred of images and few thousands of lesion cells, DCCL dataset has the largest data volume with greater than ten thousands of images and 28 thousands of lesion cells, which come from the largest CAP-accredited laboratory in China. The lesion cell types were classified following TBS criteria [3], and the high-quality dataset was thoroughly labeled and annotated by the highly experienced cytopathologists. It was very time-consuming, laborious and costly process. The dataset will be released and be publically available for the traditional machine learning and deep learning studies. It is very valuable and the blessedness for the development of AI-aided cervical cancer screening.

\section{Reference}

1. Zhang CZ, Liu D, Wang LJ, Li YX, Chen XS, et al. (2019) DCCL: A Benchmark for Cervical Cytology Analysis. In: Shen D, Liu T, Peters TM, Staib LH, Essert C, et al. (eds.). Medical Image Computing and Computer Assisted Intervention (MICCAI), Shenzhen, China.
2. Zhang CZ, Liu D, Wang LJ, Li YX, Chen XS, et al. (2019) DCCL: A Benchmark for Cervical Cytology Analysis. In: Zhang CZ, Liu D, Wang LJ, Li YX, Chen XS, et al. (eds.). International Workshop on Machine Learning in Medical Imaging, Springer Nature, Switzerland, Pg no: 6372 .

3. Nayar R, Wilbur DC (2015) The Pap Test and Bethesda 2014. Acta Cytologica 59: 121-32.

4. Tucker JH (1976) CERVISCAN: an image analysis system for experiments in automatic cervical smear prescreening. Comput Biomed Res 9: 93-107.

5. https://cs.adelaide.edu.au/simcarneiro/isbi15 challenge/

6. Bora K, Chowdhury M, Mahanta LB, Kundu MK, Das AK (2017) Automated classification of Pap smear images to detect cervical dysplasia. Comput Methods Programs Biomed 138: 31-47.

7. Zhang L, Le Lu, Nogues I, Summers RM, Liu S, et al. (2017) DeepPap: Deep Convolutional Networks for Cervical Cell Classification. IEEE Journal of Biomedical and Health Informatics 21: 1633-1643.

8. William W, Ware A, Basaza-Ejiri AH, Obungoloch J (2019) A pap-smear analysis tool (PAT) for detection of cervical cancer from pap-smear images. Biomed Eng Online 18: 16. 


\section{Hit}

Journal of Anesthesia \& Clinical Care

Journal of Addiction \& Addictive Disorders

Advances in Microbiology Research

Advances in Industrial Biotechnology

Journal of Agronomy \& Agricultural Science

Journal of AIDS Clinical Research \& STDs

Journal of Alcoholism, Drug Abuse \& Substance Dependence

Journal of Allergy Disorders \& Therapy

Journal of Alternative, Complementary \& Integrative Medicine

Journal of Alzheimer's \& Neurodegenerative Diseases

Journal of Angiology \& Vascular Surgery

Journal of Animal Research \& Veterinary Science

Archives of Zoological Studies

Archives of Urology

Journal of Atmospheric \& Earth-Sciences

Journal of Aquaculture \& Fisheries

Journal of Biotech Research \& Biochemistry

Journal of Brain \& Neuroscience Research

Journal of Cancer Biology \& Treatment

Journal of Cardiology: Study \& Research

Journal of Cell Biology \& Cell Metabolism

Journal of Clinical Dermatology \& Therapy

Journal of Clinical Immunology \& Immunotherapy

Journal of Clinical Studies \& Medical Case Reports

Journal of Community Medicine \& Public Health Care

Current Trends: Medical \& Biological Engineering

Journal of Cytology \& Tissue Biology

Journal of Dentistry: Oral Health \& Cosmesis

Journal of Diabetes \& Metabolic Disorders

Journal of Dairy Research \& Technology

Journal of Emergency Medicine Trauma \& Surgical Care

Journal of Environmental Science: Current Research

Journal of Food Science \& Nutrition

Journal of Forensic, Legal \& Investigative Sciences

Journal of Gastroenterology \& Hepatology Research

Journal of Gerontology \& Geriatric Medicine
Journal of Genetics \& Genomic Sciences

Journal of Hematology, Blood Transfusion \& Disorders

Journal of Human Endocrinology

Journal of Hospice \& Palliative Medical Care

Journal of Internal Medicine \& Primary Healthcare

Journal of Infectious \& Non Infectious Diseases

Journal of Light \& Laser: Current Trends

Journal of Modern Chemical Sciences

Journal of Medicine: Study \& Research

Journal of Nanotechnology: Nanomedicine \& Nanobiotechnology

Journal of Neonatology \& Clinical Pediatrics

Journal of Nephrology \& Renal Therapy

Journal of Non Invasive Vascular Investigation

Journal of Nuclear Medicine, Radiology \& Radiation Therapy

Journal of Obesity \& Weight Loss

Journal of Orthopedic Research \& Physiotherapy

Journal of Otolaryngology, Head \& Neck Surgery

Journal of Protein Research \& Bioinformatics

Journal of Pathology Clinical \& Medical Research

Journal of Pharmacology, Pharmaceutics \& Pharmacovigilance

Journal of Physical Medicine, Rehabilitation \& Disabilities

Journal of Plant Science: Current Research

Journal of Psychiatry, Depression \& Anxiety

Journal of Pulmonary Medicine \& Respiratory Research

Journal of Practical \& Professional Nursing

Journal of Reproductive Medicine, Gynaecology \& Obstetrics

Journal of Stem Cells Research, Development \& Therapy

Journal of Surgery: Current Trends \& Innovations

Journal of Toxicology: Current Research

Journal of Translational Science and Research

Trends in Anatomy \& Physiology

Journal of Vaccines Research \& Vaccination

Journal of Virology \& Antivirals

Archives of Surgery and Surgical Education

Sports Medicine and Injury Care Journal

International Journal of Case Reports and Therapeutic Studies

Submit Your Manuscript: http://www.heraldopenaccess.us/Online-Submission.php 